\title{
CONDENSER OPTIMIZATION OF HEAT PIPE
}

Construction of heat exchanger assembly has important role for efficient operation of energy systems. Within this assembly a heat pipe is utilized for heat transfer. The condensation part of the heat pipe is situated on top of the heating zone. The device placed in the heating zone is condenser which is used for efficient heat transfer from one medium to another. The thermal oil is used as cooling medium in the condenser. This paper analyzes the effect of different operation conditions of thermal oil to thermal performance. From the collected results it is obvious that the larger mass flow and higher temperature cause better thermal performance and lower pressure drop.

Keywords: Condenser, heat pipe, efficiency.

\section{Introduction}

Heat pipes can be used to enhance the amount of heat transfer. Since heat transmitted through a heat pipe is based on phase change, it can be pointed out that using a heat pipe with similar dimensions of a solid metal pipe, larger amounts of heat transfer will be obtained [1]. Due to the two-phase characteristics, the heat pipe is ideal for transferring heat over long distances with a very small temperature drop and for creating a nearly isothermal surface for temperature stabilization. As the working fluid operates in a thermodynamic saturated state, heat is transported using the latent heat of vaporization instead of sensible heat or conduction where the heat pipe then operates in a nearly isothermal condition [2 and 3].

Their application is wide and can be used, for example, in energy conservation, such as heat recovery in hot exhaust gas system, and for use in domestic and industrial applications. Solar heating is also another example for the application of heat pipes [4 and 5]. For example, a heat pipe solar collector is widely used nowadays [6 and 7].

Optimization of condenser plays important role in efficient operation of the system. In order to improve the performance of condenser it is required to elaborate thermal analysis for different mass flows and temperatures. In this article different power of condenser in regard to various mass flows and the temperatures on the heat pipe of condenser are investigated.

\section{Condenser design}

In this section, the heat power and pressure drop of condenser are calculated. The investigated system consists of the condenser (see Fig. 1). Condenser is placed on the heating zone of heat pipe and is used for efficient heat transfer from one medium to another. The water is used as a working fluid in the heat pipe and in the condenser is used thermal oil as cooling medium which is pumped through the connection (see Fig. 1).

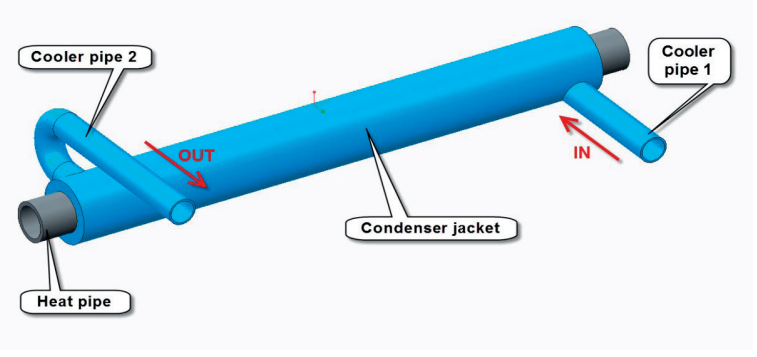

Fig. 1 Heat pipe condenser

The main objective of this work was to identify the pressure build-up in the condenser ( $\mathrm{dP})$, the outlet temperature of the thermal oil (Tout) and the output effect (quantity $\mathrm{kW}$ added to the thermal oil).

This task was done for the different temperatures on the heat pipe $100^{\circ} \mathrm{C}-150^{\circ} \mathrm{C}-200^{\circ} \mathrm{C}-250^{\circ} \mathrm{C}-300^{\circ} \mathrm{C}$ (the temperature was constant over the whole surface), with flow 10-20-30-40 g/s of thermal oil, with the fixed inlet temperature of $80^{\circ} \mathrm{C}$. The aim of

\footnotetext{
* ${ }^{1}$ Radovan Nosek, ${ }^{1}$ Stanislav Gavlas, ${ }^{1}$ Richard Lenhard, ${ }^{2}$ Veroslav Sedlak, ${ }^{2}$ Havard Mollerhagen Arvesen ${ }^{1}$ Department of Power Engineering, Faculty of Mechanical Engineering, University of Zilina, Slovakia ${ }^{2}$ Goodtech Recovery Technology AS, Norway

E-mail: radovan.nosek@fstroj.uniza.sk
} 
the task is to design stationary simulation of the heat exchanger to cool the condenser of the heat pipe.

\section{CFD Modelling}

Computer modelling reduces the total effort required in the experiment design and data acquisition. Numerical simulation of this case was used in order to predict fluid flow, heat transfer and pressure over the condenser.

\section{Physical model}

The 3D model of a heat exchanger was created based on the drawings and subsequently was modified to be able to use simulations in finite volume. Calculated model consists of a heated finned tube, jacket and oil (see Fig. 2).

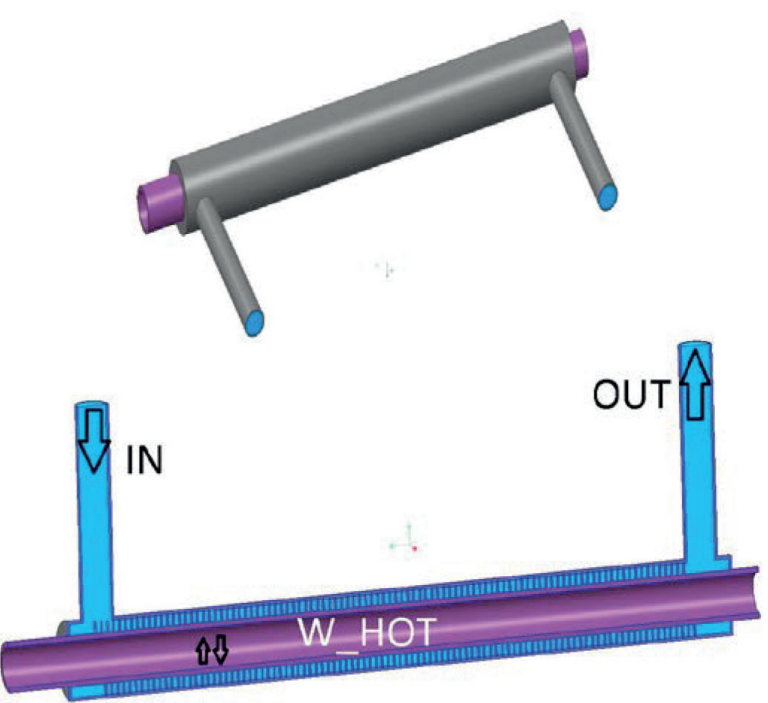

Fig. 2 Heat pipe condenser-cross section

Thermal oil is pumped in through the connection and then it spins around the heat pipe via the three parallel tracks before it comes out again through the second connection.

The most important part of the work was the determination of the detailed boundary conditions. In Table 1 are boundary conditions that were set at the inlet of condenser.

\section{Analysis of results}

In this section are presented results of numerical solution for the heat pipe condenser. In Fig. 3 is shown a position of the line where the output temperatures were calculated. This line is situated in the middle of distance between the jacket and heat pipe. In this point average values of temperature and pressure were calculated.

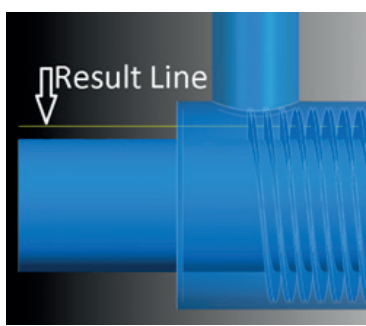

Fig. 3 Position of the result line

Results of case No. 1:

- Numerical simulations for mass flow of thermal oil $0.01 \mathrm{~kg} \cdot \mathrm{s}^{-1}$;

- Temperature on the heat pipe was set as follows: $100^{\circ} \mathrm{C}$ $150^{\circ} \mathrm{C}-200^{\circ} \mathrm{C}-250^{\circ} \mathrm{C}-300^{\circ} \mathrm{C}$.

In Table 2 are presented results of five different simulations for following parameters:

- Output temperature of the thermal oil (Tout)

- Heat power of the condenser $(\mathrm{Q})$

- Differential pressure over the condenser (dP)

Case 1

Table 2

\begin{tabular}{|c|c|c|c|c|}
\hline \multicolumn{2}{|c|}{ Mass flow } & \multicolumn{2}{|c|}{ Tin } & \multirow{2}{*}{} \\
\cline { 1 - 4 } $\mathbf{0 . 0 1}$ & kg.s $^{-1}$ & 80 & ${ }^{\circ} \mathrm{C}$ & \\
\hline Parameter & T - Heat Pipe & Tout & Q & dP \\
\hline Units & ${ }^{\circ} \mathrm{C}$ & ${ }^{\circ} \mathrm{C}$ & $\mathrm{W}$ & $\mathrm{Pa}$ \\
\hline 1 & 100 & $\mathbf{9 7}$ & $\mathbf{3 8 6}$ & $\mathbf{6 7 1 8}$ \\
\hline 2 & 150 & $\mathbf{1 4 0}$ & $\mathbf{1 3 7 1}$ & $\mathbf{4 9 7 2}$ \\
\hline 3 & 200 & $\mathbf{1 8 2}$ & $\mathbf{2 4 5 5}$ & $\mathbf{4 0 4 3}$ \\
\hline 4 & 250 & $\mathbf{2 2 4}$ & $\mathbf{3 6 3 3}$ & $\mathbf{3 2 8 2}$ \\
\hline 5 & 300 & $\mathbf{2 6 6}$ & $\mathbf{4 9 2 0}$ & $\mathbf{2 6 5 8}$ \\
\hline
\end{tabular}

The purpose of this section is to evaluate effect of different temperatures on the heat pipe to the output temperature of the thermal oil. Figure 4 shows the dependence of temperatures on the length of the condenser.

Boundary conditions

Table 1

\begin{tabular}{|c|c|c|c|c|}
\hline \multirow{2}{*}{ Name } & \multirow{2}{*}{ Type } & \multicolumn{3}{|c|}{ Set parameters } \\
\cline { 3 - 5 } & & Mass flow $\left(\mathrm{kg} \cdot \mathrm{s}^{-1}\right)$ & Temperature $\left({ }^{\circ} \mathrm{C}\right)$ & Turbulence $(\%)$ \\
\hline IN & Mass-flow-inlet & $0.01-0.04$ & 80 & 10 \\
\hline OUT & Pressure-outlet & - & - & 10 \\
\hline Surface of the heat pipe & Wall & - & $100-300$ & - \\
\hline
\end{tabular}




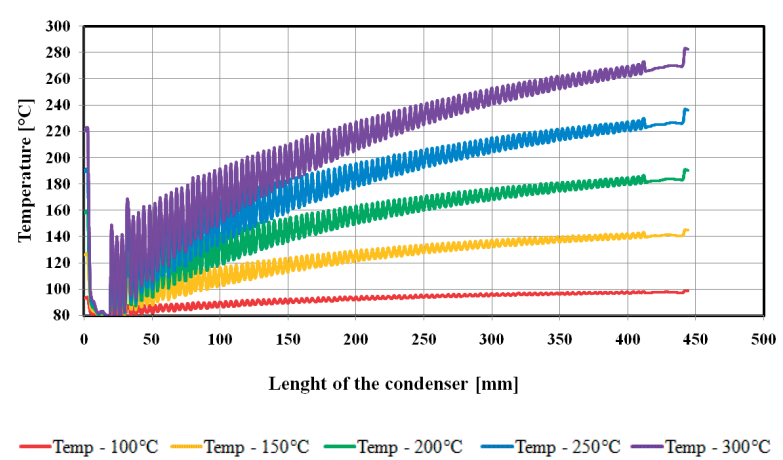

Fig. 4 Temperature dependence over the length of the condenser - Mass flow $0.01 \mathrm{~kg} \cdot \mathrm{s}^{1}$

Results of case No. 2:

- Numerical simulations for mass flow of thermal oil $0.02 \mathrm{~kg} . \mathrm{s}^{-1}$;

- Temperature on the heat pipe was set as follows: $100^{\circ} \mathrm{C}$ $150^{\circ} \mathrm{C}-200^{\circ} \mathrm{C}-250^{\circ} \mathrm{C}-300^{\circ} \mathrm{C}$.

Table 3 presents results of numerical simulations for the condenser.

Case 2

Table 3

\begin{tabular}{|c|c|c|c|c|}
\hline \multicolumn{2}{|c|}{ Mass flow } & \multicolumn{2}{|c|}{ Tin } & \\
\hline 0.02 & $\mathrm{~kg} \cdot \mathrm{s}^{-1}$ & 80 & ${ }^{\circ} \mathrm{C}$ & \\
\hline Parameter & T - Heat Pipe & Tout & Q & $\mathrm{dP}$ \\
\hline Units & ${ }^{\circ} \mathrm{C}$ & ${ }^{\circ} \mathrm{C}$ & W & $\mathrm{Pa}$ \\
\hline 1 & 100 & 93 & 591 & 17189 \\
\hline 2 & 150 & 127 & 2134 & 14061 \\
\hline 3 & 200 & 161 & 3797 & 11820 \\
\hline 4 & 250 & 194 & 5609 & 9893 \\
\hline 5 & 300 & 229 & 7526 & 8492 \\
\hline
\end{tabular}

This section presents distribution of temperature on the length of the condenser with flow $0.02 \mathrm{~kg} . \mathrm{s}^{-1}$ of thermal oil.

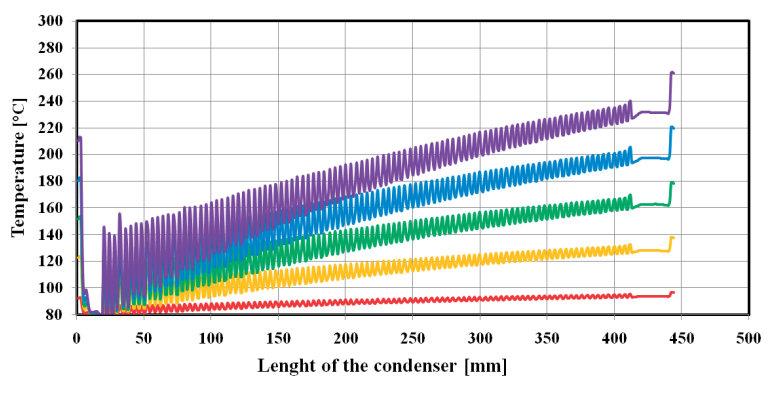

-Temp $-100^{\circ} \mathrm{C}$ - Temp $-150^{\circ} \mathrm{C}$-Temp $-200^{\circ} \mathrm{C}$ - Temp $-250^{\circ} \mathrm{C}$ - Temp $-300^{\circ} \mathrm{C}$

Fig. 5 Temperature dependence over the length of the condenser - Mass flow $0.02 \mathrm{~kg} \cdot \mathrm{s}^{-1}$
Figure 5 compares the predicted effect of temperature on the heat pipe to the output temperature at the condenser.

Results of case No. 3:

- Numerical simulations for mass flow of thermal oil $0.03 \mathrm{~kg}_{\mathrm{s}} \mathrm{s}^{-1}$.

- Temperature on the heat pipe was set as follows: $100^{\circ} \mathrm{C}$ $150^{\circ} \mathrm{C}-200^{\circ} \mathrm{C}-250^{\circ} \mathrm{C}-300^{\circ} \mathrm{C}$.

Table 4 presents results of numerical simulations for the condenser.

Case 3

Table 4

\begin{tabular}{|c|c|c|c|c|}
\hline \multicolumn{2}{|c|}{ Mass flow } & \multicolumn{2}{c|}{ Tin } & \multirow{2}{*}{} \\
\cline { 1 - 4 } $\mathbf{0 . 0 3}$ & kg.s $^{-1}$ & 80 & ${ }^{\circ} \mathrm{C}$ & \\
\hline Parameter & T - Heat Pipe & Tout & Q & dP \\
\hline Units & ${ }^{\circ} \mathrm{C}$ & ${ }^{\circ} \mathrm{C}$ & $\mathrm{W}$ & $\mathrm{Pa}$ \\
\hline 1 & 100 & 91 & $\mathbf{7 3 2}$ & $\mathbf{3 0 4 8 3}$ \\
\hline 2 & 150 & 119 & $\mathbf{2 6 5 5}$ & $\mathbf{2 5 7 2 5}$ \\
\hline 3 & 200 & 148 & $\mathbf{4 7 2 3}$ & $\mathbf{2 1 4 7 6}$ \\
\hline 4 & 250 & 177 & $\mathbf{6 9 1 7}$ & $\mathbf{1 8 5 7 6}$ \\
\hline 5 & 300 & 205 & $\mathbf{9 2 3 2}$ & $\mathbf{1 6 2 4 3}$ \\
\hline
\end{tabular}

This section presents distribution of temperature on the length of the condenser with flow $0.03 \mathrm{~kg} . \mathrm{s}^{-1}$ of thermal oil.

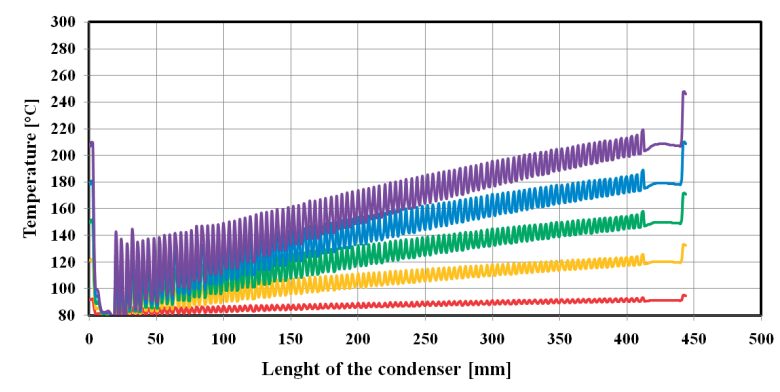

-Temp $-100^{\circ} \mathrm{C}$-Temp $-150^{\circ} \mathrm{C}$-Temp $-200^{\circ} \mathrm{C}$ - Temp $-250^{\circ} \mathrm{C}$ - Temp $-300^{\circ} \mathrm{C}$

Fig. 6 Temperature dependence over the length of the condenser-Mass flow $0.03 \mathrm{~kg} . \mathrm{s}^{-1}$

The purple curve (temperature on the heat pipe $-300^{\circ} \mathrm{C}$ ) presents the maximum difference between temperature at the inlet and outlet (Fig. 6).

Results of case No. 4:

Numerical simulations for mass flow of thermal oil $0.04 \mathrm{~kg} \cdot \mathrm{s}^{-1}$. - Temperature on the heat pipe was set as follows: $100^{\circ} \mathrm{C}$ $150^{\circ} \mathrm{C}-200^{\circ} \mathrm{C}-250^{\circ} \mathrm{C}-300^{\circ} \mathrm{C}$.

Table 5 presents results of numerical simulations for the condenser. 
Case 4

\begin{tabular}{|c|c|c|c|c|}
\hline \multicolumn{2}{|c|}{ Mass flow } & \multicolumn{2}{c|}{ Tin } & \multirow{2}{*}{} \\
\cline { 1 - 3 } $\mathbf{0 . 0 4}$ & ${\mathrm{kg} . \mathrm{s}^{-1}}^{-1}$ & 80 & ${ }^{\circ} \mathrm{C}$ & \\
\hline Parameter & T - Heat Pipe & Tout & $\mathrm{Q}$ & $\mathrm{dP}$ \\
\hline Units & ${ }^{\circ} \mathrm{C}$ & ${ }^{\circ} \mathrm{C}$ & $\mathrm{W}$ & $\mathrm{Pa}$ \\
\hline 1 & 100 & 90 & $\mathbf{8 4 7}$ & $\mathbf{4 5 1 1 2}$ \\
\hline 2 & 150 & 114 & $\mathbf{3 0 6 6}$ & $\mathbf{3 8 4 9 2}$ \\
\hline 3 & 200 & 139 & $\mathbf{5 4 3 5}$ & $\mathbf{3 2 3 9 6}$ \\
\hline 4 & 250 & 164 & $\mathbf{7 9 0 6}$ & $\mathbf{2 8 6 0 0}$ \\
\hline 5 & 300 & 188 & $\mathbf{1 0 5 0 9}$ & $\mathbf{2 5 4 4 0}$ \\
\hline
\end{tabular}

This section presents distribution of temperature on the length of the condenser with flow $0.04 \mathrm{~kg} \cdot \mathrm{s}^{-1}$ of thermal oil.

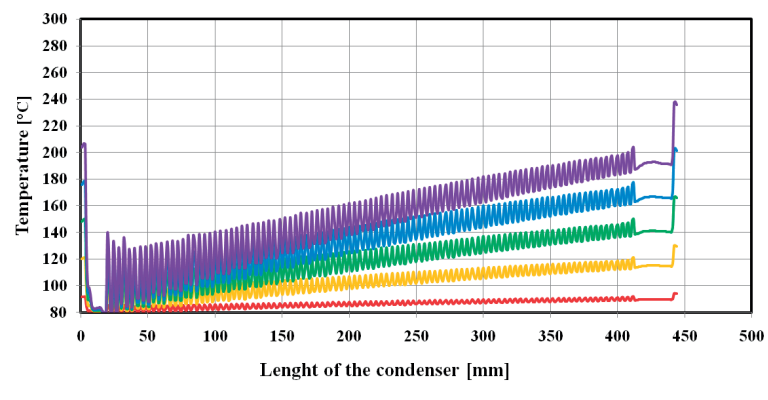

—Temp $-100^{\circ} \mathrm{C}$ - Temp $-150^{\circ} \mathrm{C}$-Temp $-200^{\circ} \mathrm{C}$-Temp $-250^{\circ} \mathrm{C}$ - Temp $-300^{\circ} \mathrm{C}$

Fig. 7 Temperature dependence over the length of the condenser - Mass flow $0.04 \mathrm{~kg} . \mathrm{s}^{-1}$

The purple curve (temperature on the heat pipe $-300^{\circ} \mathrm{C}$ ) presents the highest difference between temperature at the inlet and outlet (Fig. 7). In this case the highest heat power of condenser was also calculated.

\section{Summary}

The aim of this work was to analyse the pressure build-up in the condenser and thermal power of the condenser for different temperatures on the heat pipe. Figures 8 and 9 show the dependence of the thermal power and the pressure differences of condenser for different flows.

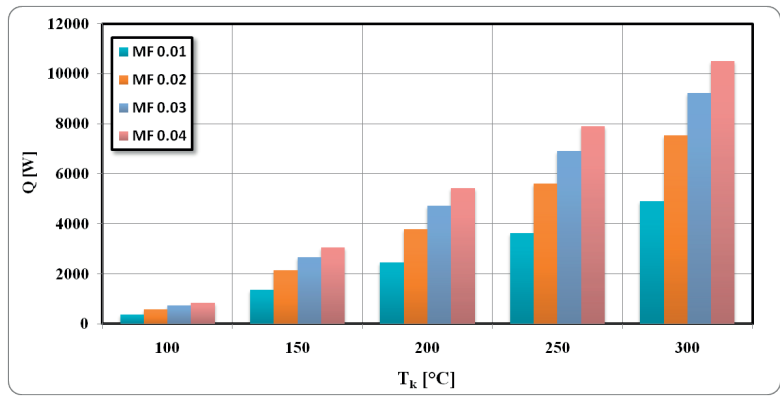

Fig. 8 Thermal power of condenser for different Mass flows (MF)

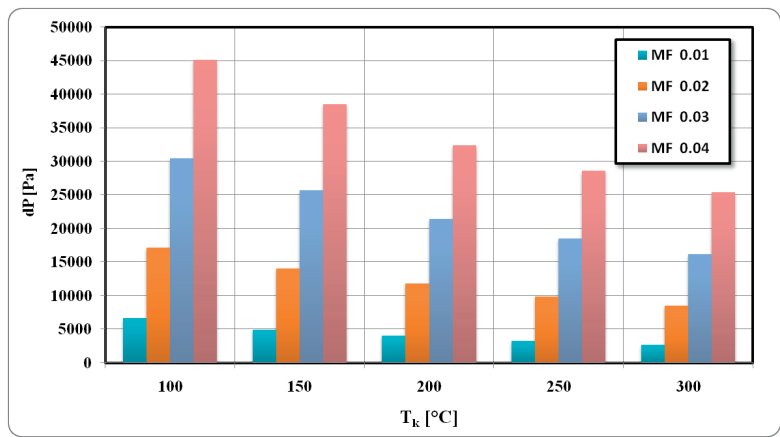

Fig. 9 Differential pressure over the condenser for different Mass flows (MF)

\section{Conclusion}

Calculated data were compared and following conclusions were reached. The highest thermal power of condenser was observed in case No. 4 (mass flow $0.04 \mathrm{~kg} . \mathrm{s}^{-1}$ and temperature on the heat pipe $300^{\circ} \mathrm{C}$ ). The lowest differential pressure over the condenser was noticed in case No. 1 (mass flow $0.01 \mathrm{~kg} . \mathrm{s}^{-1}$ and temperature on the heat pipe $300^{\circ} \mathrm{C}$ )

In the case of differential pressure the pressure drop is observed with the increase of temperature. When the flow of thermal oil increases, the condenser reaches higher heat performance. This effect can be very well observed when the temperature on the heat pipe is $300^{\circ} \mathrm{C}$. At a flow rate $0.01 \mathrm{~kg} . \mathrm{s}^{-1}$ only half of heat power is achieved in comparison with the flow $0.04 \mathrm{~kg} \cdot \mathrm{s}^{-1}$.

\section{Acknowledgements}

This work is supported by the financial assistance of the company Goodtech Recovery Technology AS.

This article is supported by the financial assistance of the project VEGA No. 1/1353/12.

The research is supported by European regional development fund and Slovak state budget by the project Research centre of University of Zilina, ITMS 26220220183. 


\section{COMMNICOIIIONS}

\section{References}

[1] JEBRAIL, F. F., ANDREWS, M. J.: Energy Research, 21, 101-112, (1998).

[2] HOLUBCIK, M., HUZVAR, J., JANDACKA J.: Combined Production of Heat and Electricity with Use of Micro Cogeneration, IN-TECH 2011 - proc. of intern. conference on innovative technologies, Bratislava, Slovakia. - [S.1.]: Jan Kudlacek, 2011. ISBN 978-80-904502-6-4. - S. 200-202.

[3] HUZVAR, J., KAPJOR, A.: Micro-cogeneration Incl. the Conversion of Chemical Energy of Biomass to Electric Energy and the Low Potential Heat, vol. 1337, 2011, 40-42, $4^{\text {th }}$ Global Conference on Power Control and Optimization, Sarawak.

[4] LENHARD, R., MALCHO, M.: Numerical Simulation Device for the Transport of Geothermal Heat with Forced Circulation of Media. Mathematical and Computer Modelling, vol. 57, No. 1-2, 111-125, 2013, ISSN 0895-7177.

[5] NEMEC P., CAJA A., MALCHO M.: Mathematical Model for Heat Transfer Limitations of Heat Pipe, Mathematical and Computer Modelling, vol. 57, 1-2, 2013, 126-136.

[6] PILAT, P., PATSCH, M., MALCHO, M: Solar Heat Utilization for Adsorption Cooling Device, vol. 25, Article No. 01074, Conference on Experimental Fluid Mechanics, EFM 2011, Jicin, 2012.

[7] SCHMALHOFER, J., FAGHRI, A.: Heat Mass Transfer, 36, 201-212, 1993. 